\title{
Progesterone vaginal ring: Results of an acceptability study in
} Kenya

\author{
Francis Obare \\ Population Council \\ Wilson Liambila \\ Population Council \\ Chi-Chi Undie \\ Population Council \\ Harriet Birungi \\ Population Council \\ Shiphrah Kuria
}

See next page for additional authors

Follow this and additional works at: https://knowledgecommons.popcouncil.org/departments_sbsr-rh

Part of the Demography, Population, and Ecology Commons, Family, Life Course, and Society Commons, International Public Health Commons, and the Women's Health Commons How does access to this work benefit you? Let us know!

\section{Recommended Citation}

Obare, Francis, Wilson Liambila, Chi-Chi Undie, Harriet Birungi, Shiphrah Kuria, Heather Clark, Deepa Rajamani, and Saumya RamaRao. 2015. "Progesterone vaginal ring: Results of an acceptability study in Kenya." New York: Population Council. 


\section{Authors}

Francis Obare, Wilson Liambila, Chi-Chi Undie, Harriet Birungi, Shiphrah Kuria, Heather Clark, Deepa Rajamani, and Saumya RamaRao 


\section{PROGESTERONE VAGINAL RING: RESULTS OF AN ACCEPTABILITY STUDY IN KENYA}

Francis Obare

Wilson Liambila Chi-Chi Undie Harriet Birungi Shiphrah Kuria Heather Clark Deepa Rajamani Saumya RamaRao 


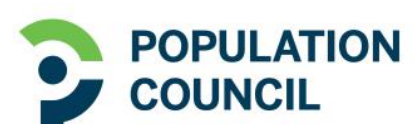 \\ Ideas. Evidence. Impact.}

The Population Council confronts critical health and development issues-from stopping the spread of HIV to improving reproductive health and ensuring that young people lead full and productive lives. Through biomedical, social science, and public health research in 50 countries, we work with our partners to deliver solutions that lead to more effective policies, programs, and technologies that improve lives around the world. Established in 1952 and headquartered in New York, the Council is a nongovernmental, nonprofit organization governed by an international board of trustees.

Population Council

General Accident House

Ralph Bunche Road

Nairobi, Kenya

Tel: +254202713480

Fax: +254202713479

popcouncil.org

Suggested citation: Obare, Francis, Wilson Liambila, Chi-Chi Undie, Harriet Birungi, Shiphrah Kuria, Heather Clark, Deepa Rajamani, and Saumya RamaRao. 2015. "Progesterone Vaginal Ring: Results of an Acceptability Study in Kenya." New York: Population Council.

(C) 2015 The Population Council, Inc. 


\section{Table of Contents}

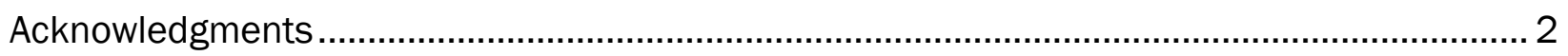

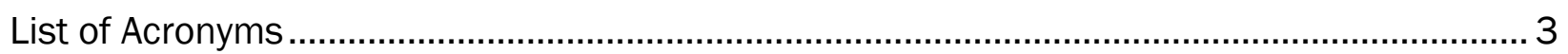

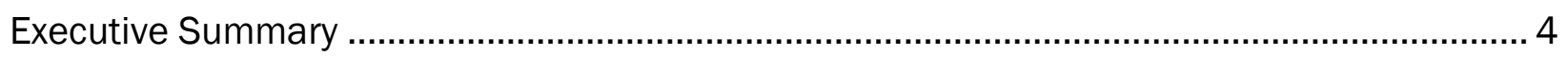

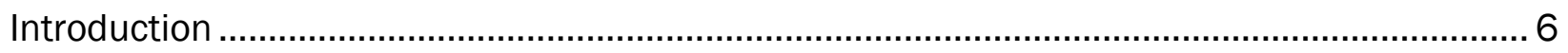

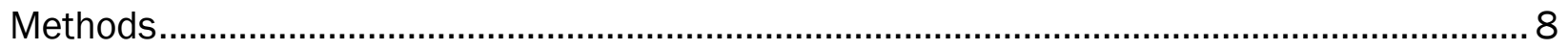

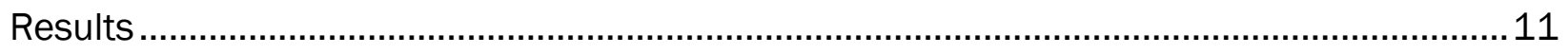

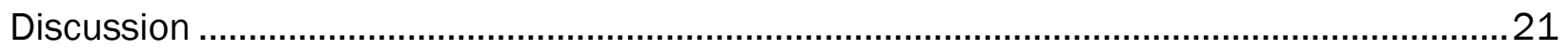

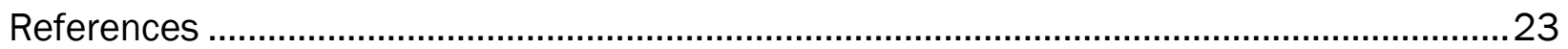

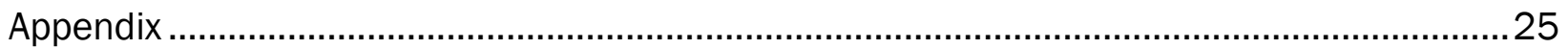




\section{Acknowledgments}

This report is based on a project funded by the Bill and Melinda Gates Foundation that aimed to determine the acceptability of the Progesterone Vaginal Ring (PVR) in sub-Saharan Africa. The project was implemented by the Population Council in collaboration with the Ministry of Health in Kenya. The Institutional Review Board (IRB) of the Population Council and the Ethics and Research Committee (ERC) of Kenyatta National Hospital/University of Nairobi granted ethical approval for the study. The National Commission for Science, Technology and Innovation (NACOSTI) granted the research permit and the Pharmacy and Poisons Board (PPB) granted the regulatory approval and import license for the rings.

We acknowledge all stakeholders (government, private, and nonprofit agencies) and individuals (Dr. David Chikamata, Dr. Juma Mwangi, and Dr. Janet Wasiche) that provided valuable input in the design and/or implementation of the project. The successful completion of the study would not have been possible without the dedication of service providers in the participating health facilities (Igegania Sub-District Hospital, Kirwara Sub-District Hospital, Makadara Health Center, Ngoliba Health Center, Ruiru Sub-District Hospital, and Thika Level 5 Hospital) and research assistants (Laura Kisivuli, Hellen Murugi, Esther Natembea, Laura Okhungu, Grace Rogena, and Maureen Yienya). We further acknowledge all the study participants who provided valuable information during the course of the study. 


\section{List of Acronyms}

$\mathrm{AE}$

CBS

CPR

ERC

FGD

GCP

IRB

IUD

IDI

KDHS

LAM

$\mathrm{MOH}$

NACOSTI

NCPD

PVR

PDA

PPB

SAE

URHI

Adverse Event

Central Bureau of Statistics

Contraceptive Prevalence Rate

Ethics and Research Committee

Focus Group Discussion

Good Clinical Practice

Institutional Review Board

Intrauterine Contraceptive Device

In-depth Interview

Kenya Demographic and Health Survey

Lactational Amenorrhea Method

Ministry of Health

National Commission for Science, Technology and Innovation

National Council for Population and Development

Progesterone Vaginal Ring

Personal Digital Assistant

Pharmacy and Poisons Board

Serious Adverse Event

Urban Reproductive Health Initiative 


\section{Executive Summary}

\section{INTRODUCTION}

The progesterone vaginal ring (PVR) is a ring-shaped device used by postpartum women to extend the contraceptive effectiveness of lactational amenorrhea. The ring is inserted in the vagina 6-9 weeks postpartum (for study purposes; 30-90 days in normal service delivery settings) for continuous use for up to 3 months and replaced with a new one if breastfeeding is continued and extended contraception is desired. The ring diffuses a continuous flow of low-dose progesterone through the vaginal walls, which enters the bloodstream and regulates the woman's fertility by suppressing ovulation. Previous studies have shown that contraceptive vaginal rings are safe, effective, and well accepted in varied cultural settings. However, the extent to which the ring is acceptable in the sub-Saharan African context is unknown, especially since vaginal rings are a new technology and use of vaginal products such as tampons is limited in the region.

\section{STUDY OBJECTIVES}

This study examined the acceptability of PVR in Kenya as part of a larger project that was also conducted in Nigeria and Senegal. The specific objectives of the study were to assess the factors influencing the acceptability of the method among clients, their spouses, providers, community members, and those who were counseled on but did not choose the method.

\section{METHODS}

The study involved prospective follow-up of participants who chose the ring (PVR users) for up to 6 months or two ring cycles, interviews with providers at baseline and endline, as well as cross-sectional interviews with women who were counseled on but did not choose the ring (PVR nonusers) and key stakeholders. A total of 60 PVR users were enrolled for follow-up, another 5 PVR users were enrolled for in-depth interviews, and 58 nonusers were interviewed upon exit. Data collection involved completion of case record forms by providers during enrollment; quantitative exit interviews with clients during enrollment, at 3 months, and at 6 months following ring use or at discontinuation; quantitative exit interviews with PVR nonusers; in-depth interviews with a subset of PVR users at 1 month, 3 months, and 6 months following ring use; in-depth interviews with spouses of PVR users at endline; focus group discussions with community leaders at endline; and self-administered interviews with providers at baseline and endline. Analysis of the quantitative data entailed simple frequencies. Directed content analysis techniques were employed for analyzing the qualitative data.

\section{KEY FINDINGS}

- Acceptability of the ring: The majority of participants who completed the two ring cycles indicated that they would use the ring in the future (92\%), their partners or family members would support future use (87\%), they would recommend or had already recommended the ring to their friends or family members $(92 \%$ and $73 \%$, respectively), and that they were willing to pay for the method $(77 \%)$. In addition, some participants were encouraged by their spouses to use the ring. There were also remarkable positive changes between baseline and follow-up in the perceptions of participants and providers about the ring.

- Reasons for choosing the ring: The most commonly cited reason for choosing the ring among users was that the method is user-controlled (49\%). The second major reason was perceived fewer side effects (46\%). In addition, some participants chose the ring just to try a new method (14\%), while others chose it because their preferred method was not available at the time of the visit (5\%). Most users also found the ring easy to insert, remove, and reinsert. 
- Client profile: The majority of women who chose the ring were aged $20-29$ years (77\%), had at least secondary level education (60\%), and resided in urban or peri-urban areas (67\%). In addition, the majority of PVR users had given birth to at least 2 children (54\%) and wanted to space the next birth by at least 4 years $(71 \%)$.

- Prior use of family planning: Slightly more than one-third of PVR users (37\%) were new family planning users. Among women who had previously used a method, the methods ever used were pills (55\%), injectables (45\%), implants (10\%), emergency contraceptive pills (8\%), male condoms $(5 \%)$, intrauterine contraceptive devices-IUDs (5\%), and female condoms (3\%).

- Subsequent method choice: Those who completed two ring cycles were more likely to switch to implants and intrauterine contraceptive devices (IUDs) compared with those who terminated use $(57 \%$ versus $17 \%$ for implants and $25 \%$ versus $6 \%$ for IUDs). Switching to long-term methods was also consistent with the finding that most users desired to space the next pregnancy by at least 4 years.

- Discontinuation of use: Participants who discontinued use of the ring did so for various reasons including ring expulsion, experiencing side effects, nonadherence to use instructions, opposition by mother-in-law, husband/partner discomfort during sex, misconception about the method, and experiencing a serious adverse event.

\section{IMPLICATIONS}

- The findings of the study indicate that the ring was acceptable to most clients and key stakeholders. In addition, several positive attributes of the ring that were mentioned by participants are likely to increase uptake of the method.

- The profile of PVR users suggests that young, educated, urban or peri-urban dwellers are likely to be the first acceptors of the method if it is introduced into the country before it diffuses to other segments of the population.

- The reasons given for choosing the ring and the fact that about one-third of the participants were new users suggest that the method is likely to expand contraceptive choice during the postpartum period, enhance women's autonomy in contraceptive use, and sustain or contribute to an increased contraceptive prevalence rate in the country.

- The finding that those who completed the two ring cycles mostly switched to long-term methods at the end of the study and that most users desired longer birth spacing suggests that programs delivering the ring need to consider mechanisms for bridging users to long-term methods.

- Given that the ring is a user-controlled method, service-delivery programs should consider ways of ensuring that clients obtain information on correct use, including proper insertion and adherence to use instructions, such as not leaving the ring out for long. Proper insertion and adhering to use instructions are, in turn, likely to reduce instances of ring expulsion and discontinuation. 


\section{Introduction}

The progesterone vaginal ring (PVR) is used to extend the contraceptive effectiveness of lactational amenorrhea among breastfeeding women. The ring is inserted in the vagina 6-9 weeks postpartum for study purposes (30-90 days in normal service delivery conditions) for continuous use for up to 3 months and replaced with a new one if breastfeeding is continued and extended contraception is desired. Women can use four rings successively for up to one year postpartum. PVR functions by diffusing a continuous flow of progesterone through the vaginal walls-approximately $10 \mathrm{mg}$ per day-which then enters the bloodstream and regulates the woman's fertility by suppressing ovulation. Progesterone also thickens the cervical mucus thereby inhibiting sperm penetration into the uterus. Clinical trials have demonstrated that PVR is an effective contraceptive method (Sivin et al. 1997; Massai et al. 1999). The method was first registered in Chile and Peru in 1998 for use by postpartum women but has since been expanded to other Latin American countries, including Bolivia, the Dominican Republic, Ecuador, and Guatemala (Reproductive Health Supplies Coalition [RHSC] 2011).

Previous studies conducted by the Population Council have demonstrated that vaginal rings are well accepted in settings as culturally diverse as Australia, Egypt, Latin America, Singapore, and the United States (RHSC 2011). However, the extent to which PVR is acceptable in the sub-Saharan African context is unknown, especially since vaginal rings are a new technology in this setting and use of vaginal products such as tampons is limited in the region. An understanding of the acceptability of the ring is important for informing the introduction of the method in the region. Sub-Saharan Africa in particular presents an opportunity for expanding the use of the method given relatively long breastfeeding durations; high unmet need for contraception, especially during the postpartum period; and the potential for multiple channels of introducing the method to potential users, including public and private clinics as well as private pharmacies and community distribution systems (Haggerty and Rutstein 1999; Westoff 2012). Moreover, since the use of PVR is predicated upon women breastfeeding at least four times a day, it provides an opportunity to promote breastfeeding while ensuring contraceptive protection, thereby benefiting both mothers and their infants.

To understand the extent of acceptability of the method in the region, the Population Council conducted acceptability studies in Kenya, Nigeria, and Senegal. This report presents findings from the study in Kenya. The study was one component of a number of activities aimed at informing the introduction of the method in the country. Other activities included global and national consultations with key stakeholders, assessments and documentation of the regulatory and procurement frameworks, and market segmentation and demand analysis.

\section{STUDY OBJECTIVES}

This study examined the acceptability of PVR in Kenya as part of a larger project that was also conducted in Nigeria and Senegal. The specific objective of the study was to assess the factors influencing the acceptability of the method among clients, their spouses, providers, community members, and women who were counseled on but did not choose the method. 


\section{STUDY CONTEXT}

Estimates from the Kenya Demographic and Health Surveys (KDHS) show that the contraceptive prevalence rate (proportion of currently married women using any method of contraception) more than doubled over a period of a quarter century from 27\% in 1989 to 58\% in 2014 (National Council for Population and Development [NCPD] and Institute for Resource Development/Macro Systems 1989; Kenya National Bureau of Statistics [KNBS] et al. 2015). Over the same period, the use of modern methods increased almost three-fold from 18\% in 1989 to 53\% in 2014 (NCPD and Institute for Resource Development/Macro Systems 1989; KNBS et al. 2015). In spite of the improvements, contraceptive use remained lower than the national average in rural areas. Contraceptive use was also lowest among young women aged 15-19 years, those with no education, and those from the poorest households. In addition, estimates from the 2008-09 KDHS showed that only $25 \%$ of postpartum women were using a family planning method compared with the national contraceptive prevalence rate (CPR) of $46 \%$ at that time (Gebreselassie et al. 2008; KNBS and ICF Macro 2010).

Over time, unmet need for contraception declined by almost half from 35\% in 1993 to 18\% in 2014 (NCPD and Institute for Resource Development/Macro Systems 1989; KNBS et al. 2015). However, there was only a slight decline in unmet need between 1998 and 2008-09 from 28\% to 26\% (NCPD et al. 1999; KNBS and ICF Macro 2010). In addition, unmet need for contraception remained higher than the national average in rural areas. Unmet need also remained highest among the youngest age groups (15-24 years), those with low levels of education (no education and primary incomplete), and those from the poorest households (NCPD et al. 1999; CBS et al. 2004; KNBS and ICF Macro 2010; KNBS et al. 2015). Estimates from the 2008-09 KDHS further showed that unmet need was more than twice as high among postpartum women compared with those in the general population (68\% and 26\%, respectively) (Gebreselassie et al. 2008; KNBS and ICF Macro 2010).

Trends in contraceptive method mix show that over time, the use of modern methods has been dominated by injectables-from 19\% of all modern methods in 1989 to 55\% in 2008-09 (NCPD and Institute for Resource Development/Macro Systems 1989; KNBS and ICF Macro 2010). The trend has been accompanied by declining use of pills (from $26 \%$ to $18 \%$ ), IUDs (from $21 \%$ to $5 \%$ ), and female sterilization (from $29 \%$ to $12 \%$ ) (NCPD and Institute for Resource Development/Macro Systems 1989; KNBS and ICF Macro 2010). Moreover, the postpartum period is characterized by a limited range of available family planning methods that include the lactational amenorrhea method (LAM), IUD, sterilization, progestin-only pills, injectables, and condoms. The Ministry of Health $(\mathrm{MOH})$ therefore recognizes the need for family planning information and services during the postpartum period as an integral component of maternal and neonatal care services (DRH/MOPHS 2010). Programs to strengthen family planning service provision during the postpartum period have to date been implemented on a pilot basis in selected districts with limited stakeholder involvement to ensure sustainability (Mwangi et al. 2008; Chebet and Jahonga 2011). These programs have, however, demonstrated substantial improvements in the uptake of family planning in the postpartum period (Mwangi et al. 2008; Chebet and Jahonga 2011).

Regarding breastfeeding practices, estimates from the 2008-09 KDHS showed that nearly all children under five years of age (97\%) were ever breastfed (KNBS and ICF Macro 2010). Mothers initiated breastfeeding within one hour of birth for $58 \%$ and within one day of birth for $86 \%$ of the children ever breastfed (KNBS and ICF Macro 2010). The median duration for any breastfeeding was 21 months, while the median duration for exclusive breastfeeding was less than one month (KNBS and ICF Macro 2010). Ninety-three percent of children under the age of 6 months were breastfed 6 or more times within a 24-hour period, while $32 \%$ of children under the age of 6 months are exclusively breastfed (KNBS and ICF Macro 2010). In September 2012, parliament passed a law aimed at promoting exclusive breastfeeding for the first 6 months and continuous breastfeeding after the introduction of other foods up to a period of 24 months. The law was, however, criticized for seeking to regulate the marketing, promotion, distribution, and sale of breast milk substitutes rather than promote exclusive breastfeeding (Maina 2012). The government has also formulated several policies aimed at protecting, promoting, and supporting optimal infant feeding practices (Republic of Kenya 2012). 


\section{Methods}

\section{STUDY DESIGN}

The study used both prospective and cross-sectional designs. The prospective component involved enrolling and following up participants over a period of 6 months ( 2 ring cycles) or up to discontinuation of use of the ring. Participants were interviewed at the time of recruitment (baseline), at 3 months and 6 months if they completed the two ring cycles, or at the time they left the study if they discontinued use. Providers who were trained on the provision of the method were also interviewed at baseline and endline. The cross-sectional component involved interviews with women who were counseled on the ring but did not choose it at baseline as well as community opinion leaders and husbands of PVR users at endline.

\section{STUDY SETTING}

The study was conducted in six public health facilities (two health centers and four hospitals) in three counties in Kenya (Kiambu, Muranga, and Nairobi). The sites were selected in conjunction with the $\mathrm{MOH} /$ Kenya based on onsite availability of postpartum family planning services, a reasonable caseload of women seeking family planning before nine weeks postpartum, no other new contraceptive being introduced, the feasibility of following up participants, being project sites of the Urban Reproductive Health Initiative (URHI), ability to meet Population Council research standards and global Good Clinical Practice (GCP) guidelines, as well as the ability to absorb the workload necessitated by the study such as documentation and client follow-up. Three of the sites were located in rural areas, two in urban areas and one in a peri-urban setting. Throughout this report, the term "site" or "study site" is used to refer to the health facilities where the study was conducted.

\section{STUDY PROCEDURES}

The study was preceded by a mapping exercise that involved consultative meetings with key government, regulatory, and development agencies; social marketing organizations; research institutions; manufacturers/distributors of health commodities; community/advocacy groups; institutions involving public/private partnerships; and other organizations providing family planning services in the country. The purpose of the exercise was to determine the perspectives of the stakeholders regarding the method and the acceptability study. The next step involved obtaining the ethical, research, and regulatory approvals necessary for importation of rings into the country and for conducting the study. Ethical clearance for the study was granted by the Institutional Review Board (IRB) of the Population Council (Protocol number 562) and the Ethics and Research Committee (ERC) of Kenyatta National Hospital/University of Nairobi (Protocol number P625/11/2012). The National Commission for Science, Technology and Innovation (NACOSTI) granted the research permit for the study (Reference number NCST/5/002/R/683), while the Pharmacy and Poisons Board (PPB) granted the regulatory approval (Reference number PPB/ECCT/13/03/01/2013(93) and import license (Number T/13/6357P). The import license allowed for importation of a limited quantity of rings for research purposes only.

A total of 35 service providers from the six selected sites and four health managers/supervisors were trained on the provision of PVR. The training was organized in two separate sessions and involved approximately three providers from each health facility to avoid interfering with normal service delivery that could occur if all service providers were trained at the same time. The providers were trained on PVR and how it works, the counseling process, enrollment procedures (inclusion and exclusion criteria), good clinical practice, and completion of the relevant documentation during recruitment. Six research assistants who had social science backgrounds were also trained to conduct interviews with clients upon exit and during follow-up. The research assistants were trained on the method and how it works, study design, interviewing skills, and ethical considerations in the study. All research assistants undertook online courses on ethics and obtained certifications before being assigned to the facilities. They were stationed at the facilities throughout the duration of the study. 
Recruitment of participants into the study started in November 2013 following the training of providers and research assistants and ended in early February 2014 when the target was realized. A total of 58 clients aged 18-35 years were targeted for enrollment for quantitative interviews. A similar sample size was targeted in each of the other two countries included in the study (Nigeria and Senegal). The sample size was, however, powered to detect significant differences in all the three countries combined rather than at the individual country level. Another five participants were targeted for enrollment for in-depth interviews (IDIs) after one month of using the ring, at three months, and at six months. The study further targeted 58 participants who were counseled on the ring but did not choose the method, in order to understand the reasons guiding their choices.

The recruitment process entailed providers counseling postpartum clients seeking family planning services on all available methods including PVR so that all clients had a choice of methods. Clients who were identified from other units, such as immunization and growth monitoring, were encouraged to visit the family planning unit if they needed contraceptive services. Clients who chose the ring during counseling were directed to the research assistant who completed the written informed consent process before providers could dispense the method. Clients were informed about the study procedures including the requirement to undergo pregnancy and HIV tests as part of inclusion and exclusion criteria as well as the need for follow-up. Those clients who granted written informed consent were then directed back to the provider for medical examination. Clients who qualified for the ring after satisfying the inclusion and exclusion criteria were then specifically counseled on the method and shown how to use it.

Providers were instructed to show enrolled participants how to insert and remove the ring, and to ensure that they left the facility when the ring was properly inserted. In particular, providers were trained to insert the ring, ask participants to remove it and reinsert themselves, and confirm that they were not feeling it after reinsertion before leaving the facility. Clients who did not grant written informed consent and those who did not satisfy the inclusion and exclusion criteria after screening were offered other methods, even if they had initially chosen the ring. Clients who were given the ring were then interviewed by the research assistants upon exit. They were advised to return to the facility after three months with the used ring to obtain another one, or at any time in case of concerns regarding the use of the ring. During exit interviews, the research assistants obtained contact information to follow up with the clients in the event that they did not return to the study site.

Given that the ring was being introduced in the context of a study, there were elaborate inclusion and exclusion criteria as outlined in Appendix A1. In addition, the study monitor conducted regular site visits to ensure compliance with study procedures, good clinical practice, ethical conduct of the study, and recordings of adverse and serious adverse events, if any. Participants were also instructed to report all side effects including adverse or serious adverse events (AEs or SAEs), while providers were trained to ask and record all side effects that women reported.

\section{DATA COLLECTION}

The first component of data collection involved information captured by service providers through case record forms. These included forms for screening for eligibility, medical examination, concomitant prior medication, unscheduled visits, follow-up visits, missed visits, unscheduled calls, pregnancy outcomes (in case a participant became pregnant when using the ring), adverse events, serious adverse events, and termination of participation in the study. Some of the forms, such as those for pregnancy outcomes, were not completed because no participant experienced a pregnancy when using the ring.

The second component of data collection involved quantitative interviews with PVR users who were enrolled for prospective follow-up (Table 1). The participants were interviewed upon exit at baseline and at three and six months, or at study termination if they had discontinued. Baseline interviews captured information on background characteristics (such as age, type of place of residence, education level, marital status, occupation, and religious affiliation), reproductive history and preferences, contraceptive use, perceptions 
about the quality of care received during the visit, as well as perceptions about the PVR and other vaginally inserted products. Follow-up interviews captured information on the status of ring use, ease of use, experiences of ring expulsion, general health status during ring use, sexual activity during ring use, and the level of satisfaction with the method. Quantitative interviews were also conducted with consenting clients who were counseled on the ring but did not choose to adopt it to capture information on their characteristics, choice of method, and reasons guiding their choices.

The third component of data collection involved qualitative interviews with various stakeholders. In particular, in-depth interviews (IDIs) were conducted with additional women who were enrolled in the study (Table 1). The interviews were conducted at one, three, and six months following ring use. The interviews explored their experiences using the ring and their perceptions about the method. In-depth interviews were also conducted with three husbands of PVR users who informed their spouses that they were using the ring to determine their perceptions about the method. In addition, three focus group discussions (FGDs) were held with community stakeholders including religious leaders, women leaders, and youth leaders to determine their perceptions about the method. All qualitative interviews and discussions were audiotaped and transcribed.

Service providers also completed self-administered questionnaires at the end of training (at baseline) and at the end of participant follow-up (at endline). Information was collected on their background characteristics (such as age, sex, and technical qualification), knowledge and practices regarding postpartum family planning including PVR, perceptions about the method, and at endline, experiences dispensing the method to study participants.

\section{DATA MANAGEMENT AND ANALYSIS}

Exit interviews with PVR users at baseline and endline were conducted using personal digital assistants (PDAs). The data were then downloaded into computers at the Population Council office in Nairobi every Friday evening during the study period. Data from case record forms and provider interviews were entered in EpiData in the Population Council office. The case record forms were photocopied and copies were left at the participating facilities together with participant files. All quantitative data were exported to Stata for cleaning and analysis. Analysis involved simple frequencies.

Qualitative interviews were audiotaped, translated into English where necessary (for interviews that were conducted in Kiswahili), and transcribed in Word. A "directed approach" to content analysis (Hsieh and Shannon 2005) was employed for analyzing the interview transcripts: findings from the interviews' major domains of inquiry were used as guidance for initial codes, and this level of coding was used to generate themes across all interviews with similar populations. These themes were taken to represent respondents' general perceptions about the PVR and their experiences using it. 


\section{Results}

\section{OVERALL STUDY METRICS}

A total of 83 women were screened for eligibility for participation in the study after choosing the ring during counseling (Table 1). Out of these, 78 were targeted for inclusion in quantitative interviews while 5 were targeted for inclusion in in-depth interviews. Since information was not collected on the number of women counseled on the method during the period of recruitment, it is not possible to determine the percent of women coming for postpartum family planning who chose the PVR.

TABLE 1 Enrollment and participation in the study

\begin{tabular}{|c|c|c|}
\hline Variable & (n) & women $(77 \%)$ who were targeted for inclusion in the \\
\hline Number of women screened & 83 & quantitative interviews and all women who were targeted \\
\hline Number of women enrolled & 65 & for inclusion in the in-depth interviews. A total of 28 (43\%) \\
\hline $\begin{array}{l}\text { Number of women who completed the } \\
\text { study or used two rings }\end{array}$ & 28 & $\begin{array}{l}\text { women who were enrolled in the study completed the two } \\
\text { ring cycles (Table 1). Twenty-four of the women who }\end{array}$ \\
\hline Number of PVR nonusers & & completed the two ring cycles were included in the \\
\hline $\begin{array}{c}\text { interviewed at baseline } \\
\text { Data source: CRFs and Baselin }\end{array}$ & 58 & $\begin{array}{l}\text { quantitative interviews, while } 4 \text { were included in the in- } \\
\text { depth interviews. }\end{array}$ \\
\hline
\end{tabular}

Sixty-five of the 83 women (78\%) who were screened were found to be eligible to participate in the study and were therefore enrolled (Table 1). These comprised 60 of the 78 depth interviews.

\section{DEMOGRAPHIC CHARACTERISTICS OF STUDY PARTICIPANTS}

More than three-quarters of the women who were enrolled for the quantitative interviews (77\%) were aged $20-29$ years (Table 2). More than two-thirds (67\%) of the women were from urban or peri-urban areas, $60 \%$ had a secondary and above level of education, while nearly all (98\%) were either married or living with a man. Half of the women (50\%) were not working, although partners of $93 \%$ of them were engaged in some kind of work with the majority ( $75 \%$ ) of the partners being engaged in nonprofessional jobs such as manual/casual work and business or farming (Table 2).

Further analysis showed that, as expected, there were variations in educational attainment by type of place of residence. In particular, only half (50\%) of the rural residents had a secondary and above level of education, while about two-thirds of urban and peri-urban residents had that level of education $(67 \%$ and $64 \%$, respectively). In contrast, the proportion of respondents that were not working was highest in the urban areas and lowest in peri-urban areas (56\% in urban areas, $50 \%$ in rural areas, and $45 \%$ in peri-urban areas). However, all women who lived in urban areas reported that their partners were engaged in some form of work, while the corresponding proportions for peri-urban and rural residents were $91 \%$ and $90 \%$, respectively.
TABLE 2 Demographic characteristics of study participants

\begin{tabular}{|c|c|c|}
\hline Variable & (n) & Percent \\
\hline \multicolumn{3}{|l|}{ Age } \\
\hline $18-19$ & 4 & 6.7 \\
\hline $20-24$ & 31 & 51.7 \\
\hline $25-29$ & 15 & 25.0 \\
\hline $30-35$ & 10 & 16.7 \\
\hline \multicolumn{3}{|l|}{ Place of residence } \\
\hline Urban & 18 & 30.0 \\
\hline Peri-urban & 22 & 36.7 \\
\hline Rural & 20 & 33.3 \\
\hline \multicolumn{3}{|l|}{ Education } \\
\hline Primary or lower & 24 & 40.0 \\
\hline Secondary & 26 & 43.3 \\
\hline College/university & 10 & 16.7 \\
\hline \multicolumn{3}{|l|}{ Marital status } \\
\hline Never married & 1 & 1.7 \\
\hline Married & 58 & 96.7 \\
\hline Cohabiting & 1 & 1.7 \\
\hline \multicolumn{3}{|c|}{ Respondent's occupation } \\
\hline Not working & 30 & 50.0 \\
\hline Nonprofessional & 26 & 43.3 \\
\hline Professional & 4 & 6.7 \\
\hline \multicolumn{3}{|l|}{ Partner's occupation } \\
\hline Not working & 4 & 6.7 \\
\hline Nonprofessional & 45 & 75.0 \\
\hline Professional & 11 & 18.3 \\
\hline Total & 60 & 100.0 \\
\hline
\end{tabular}




\section{REPRODUCTIVE AND FAMILY PLANNING HISTORY}

Nearly half of the women (47\%) who were enrolled in the study had given birth to one child and almost a similar proportion (48\%) had one living child (Table 3). The majority $(63 \%)$ reported that the pregnancy for the current child was intended, although most of the women (71\%) desired to space the next pregnancy by at least four years. The majority (89\%) reported discussing pregnancy spacing with their partners. In addition, $37 \%$ of the women were new family planning users (Table 3).

TABLE 3 Reproductive history and family planning use

\begin{tabular}{lcc}
\hline Variable & $(\mathrm{n})$ & Percent \\
\hline Children ever born & & \\
1 & 28 & 46.7 \\
2 & 20 & 33.7 \\
3 or more & 12 & 20.0 \\
Number of living children & & \\
1 & 29 & 48.3 \\
2 & 19 & 31.7 \\
3 or more & 12 & 20.0 \\
Pregnancy was intended & & \\
$\quad$ Yes & 38 & 63.3 \\
$\quad$ No & 22 & 36.7 \\
Preferred spacing of next birth & & \\
$2-3$ years & 14 & 28.6 \\
$4-5$ years & 23 & 46.9 \\
6 years or more & 12 & 24.5 \\
Discussed pregnancy spacing with partner & & \\
$\quad$ Yes & 50 & 89.3 \\
$\quad$ No & 6 & 10.7 \\
Prior use of a method & & \\
Ever used & 38 & 63.3 \\
$\quad$ Never used & 22 & 36.7 \\
\hline Data source: Baseline dataset $(\mathrm{N}=60)$. & &
\end{tabular}

Further analysis showed that the proportion of new users was higher among younger (below 25 years of age) women than older ( 25 years and above) women ( $49 \%$ and $20 \%$, respectively). Similarly, the proportion of new users was about five times higher among women who had given birth to one child than among those who had two or more children ( $64 \%$ and $13 \%$, respectively).

The proportion of new users was also highest in the urban areas (44\%), followed by rural (35\%) and peri-urban areas (31\%). Similarly, the proportion of new users was more than twice as high among those with primary or lower levels of education (55\%) compared with those with a secondary and above level of education (25\%).

Among women who had previously used a method, the pill was the most common method ever used (55\%), followed by injectables (45\%), implants (10\%), and emergency pills (8\%) (Figure 1). As already noted, the contraceptive method mix in Kenya has been characterized by a declining use of pills, intrauterine contraceptive devices (IUDs), and female sterilization, and an increasing use of injectables.

\section{FIGURE 1 PREVIOUS METHOD USE}

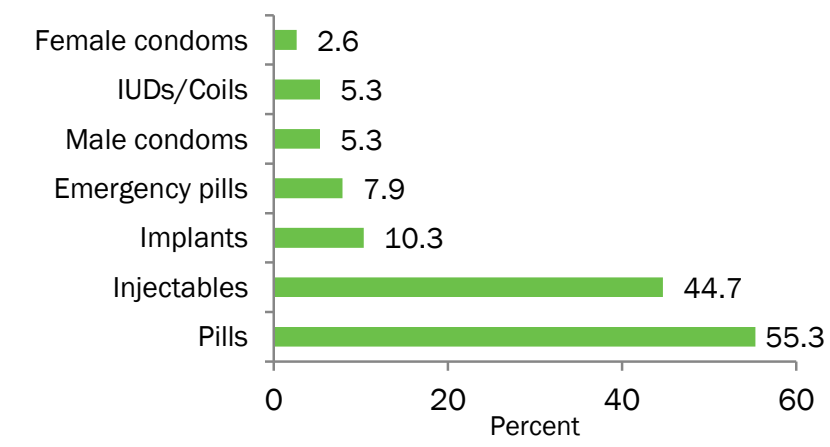

Note: Question allowed for multiple responses. Data source: Baseline dataset $(\mathrm{N}=38)$. 


\section{METHOD CHOICE AMONG PVR USERS AND NONUSERS}

Ninety-five percent of the women chose the ring as the preferred method, while $5 \%$ chose it because their preferred method (progestin-only pills) was not available at the time of the visit. The most common reasons for choosing the ring as the preferred method were that it is user-controlled (49\%); the perception that it did not have many side effects (46\%); the perception that it was safe for breastfeeding (18\%); perceived ease, comfort and convenience associated with the method (16\%); and the desire to try a new method (14\%) (Figure 2).

\section{FIGURE 2 REASONS FOR PVR CHOICE}

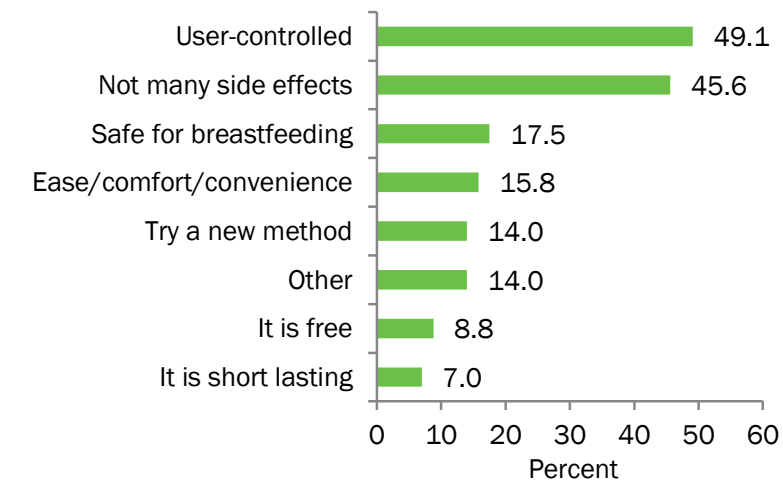

Note: Question allowed for multiple responses. Data source: Baseline dataset $(\mathrm{N}=57)$.

Among women who were counseled on the ring but did not choose it and who agreed to be interviewed upon exit, the majority (47\%) chose injectables, $34 \%$ chose progestin-only pills, $12 \%$ chose implants, $3 \%$ chose male condoms, $2 \%$ chose intrauterine contraceptive devices (IUDs), and another $2 \%$ opted to use the lactational amenorrhea method (LAM). The most commonly cited reason for choice of a particular method was that they had known it from before (39\%) (see Figure 3). Other reasons (35\%) included few or no side effects, convenience of use including secret use without partner's knowledge, preference for long-term methods, and the desire to try another method.

\section{FIGURE 3 REASONS FOR CHOOSING}

\section{OTHER METHODS}

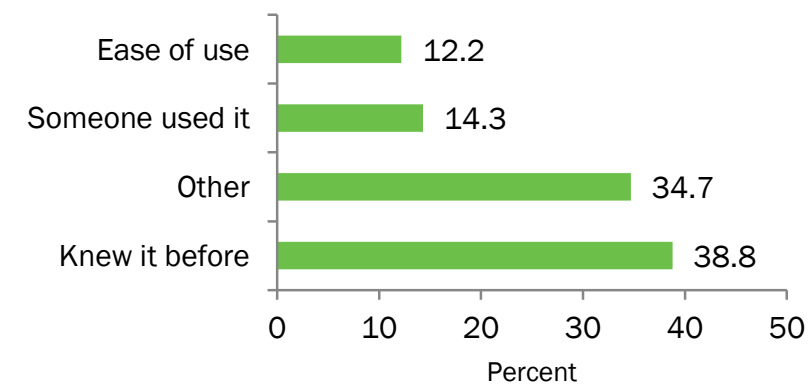

Data source: Nonuser dataset $(\mathrm{N}=58)$. 


\section{IMPRESSIONS ABOUT THE RING}

There were remarkable changes in participants' perceptions about the ring between baseline and follow-up. For instance, half of the participants (50\%) felt that the ring was too big at baseline, while at follow-up the majority of the women interviewed (93\%) reported that the size of the ring was just fine (Table 4). Similarly, the proportion of participants who felt that the color of the ring was just fine increased from $78 \%$ at baseline to $93 \%$ at follow-up. In addition, the proportion that felt that the texture of the ring was just fine increased from $53 \%$ at baseline to $86 \%$ at endline (Table 4 ).

TABLE 4 Impressions about the ring

\begin{tabular}{lrr}
\hline Indicator & Baseline, \% (N=60) & Follow-up, \% (N=42) \\
\hline Impressions about size & 1.7 & 0.0 \\
$\quad$ Too small & 50.0 & 7.1 \\
$\quad$ Too big & 48.3 & 92.9 \\
$\quad$ Just fine & & \\
Impressions about color & 21.7 & 7.1 \\
$\quad$ Too bright & 78.3 & 92.9 \\
$\quad$ Just fine & & \\
Impressions about texture & 23.3 & 11.9 \\
$\quad$ Too soft & 23.3 & 2.4 \\
$\quad$ Too hard & 53.3 & 85.7 \\
$\quad$ Just fine & &
\end{tabular}

Further analysis showed that there were no significant differences in participants' perceptions about the ring at baseline by whether they completed the two ring cycles. In particular, half of the 28 women who completed the two ring cycles and a similar proportion of those who discontinued use felt that the size of the ring was just fine, while $40 \%$, or 4 women who were eventually lost to follow-up, felt that way. Similarly, the proportion of women who felt that the color of the ring was just fine was $81 \%$ among those who completed the two cycles, $79 \%$ among those who discontinued use, and $70 \%$ among those lost to follow-up. The corresponding figures for those who felt that the texture of the ring was just fine were $58 \%, 54 \%$, and $40 \%$ among the three groups of participants respectively.

\section{PERCEIVED QUALITY OF CARE}

Interviews with participants upon exit during recruitment showed that $85 \%$ of the respondents reported that providers had counseled them about breastfeeding requirements when using the ring (Table 5). Nearly all participants $(97 \%)$ reported that providers counseled them on how and when to remove the ring, while all participants were given opportunity to ask questions. More than three-quarters (77\%) of participants were encouraged to insert the ring themselves. All participants reported that they were shown how to insert the ring, while $73 \%$ reported that providers showed them how to remove the ring (Table 5). However, some providers reported that a few clients were reluctant to touch their own genitals and expected the providers to insert the ring for them just like they do with other methods requiring insertion, such as the IUD and implants.

TABLE 5 Perceived quality of care

\begin{tabular}{llccc}
\hline Domain & Item & Response & (n) & Percent \\
\hline $\begin{array}{l}\text { Counseling on } \\
\text { the PVR } \\
\text { method }\end{array}$ & $\begin{array}{l}\text { Provider conveyed minimum breastfeeding } \\
\text { requirement }\end{array}$ & Yes & 51 & 85.0 \\
& Provider conveyed when to remove PVR & Yes & 58 & 96.7 \\
& Provider allowed respondent to ask questions & Yes & 60 & 100.0 \\
Counseling on & Provider encouraged respondent to insert PVR & Yes & 46 & 76.7 \\
PVR use & Provider showed how to insert PVR & Yes & 60 & 100.0 \\
\hline
\end{tabular}

Data source: Baseline dataset. 


\section{ACCEPTABILITY}

Eighty-percent of participants who were interviewed upon follow-up reported that they were satisfied with the ring. The proportion reporting satisfaction with the ring was nearly twice as high among those who completed the two ring cycles (100\%) than among those who terminated use (57\%). Table 6 presents the distribution of participants who expressed satisfaction and dissatisfaction with the ring by experiences of using the method. A similar proportion of satisfied and dissatisfied participants found it easy to insert the ring $(76 \%$ and $75 \%$, respectively). However, a higher proportion of dissatisfied participants compared to their satisfied counterparts found it easy to remove the ring ( $75 \%$ and $51 \%$, respectively) and to reinsert the ring ( $100 \%$ and $54 \%$, respectively). None of the satisfied and dissatisfied clients reported experiencing side effects, which could imply that participants who terminated use because of side effects were not interviewed at follow-up.

TABLE 6 Responses by satisfaction related to PVR use

\begin{tabular}{|c|c|c|c|c|c|}
\hline Domain & Item & Response & Satisfied & Not Satisfied & $\begin{array}{c}p \text { Value } \\
\text { Fisher's Exact Test }\end{array}$ \\
\hline \multirow[t]{3}{*}{ Ease of use } & Ease of inserting PVR & Easy/Very easy & $75.7 \%$ & $75.0 \%$ & 0.82 \\
\hline & Ease of removing PVR & Easy/Very easy & $51.4 \%$ & $75.0 \%$ & 0.30 \\
\hline & Ease of reinserting PVR & Easy/Very easy & $54.1 \%$ & $100.0 \%$ & 0.08 \\
\hline Side effects & Reported & No & $100.0 \%$ & $100.0 \%$ & - \\
\hline Expulsion & PVR fell out on its own & No & $86.1 \%$ & $66.7 \%$ & 0.40 \\
\hline \multirow[t]{4}{*}{ Sexual intercourse } & Feel PVR during sex & No & $88.6 \%$ & $50.0 \%$ & 0.00 \\
\hline & Partner feels PVR during sex & No & $62.9 \%$ & $25.0 \%$ & 0.29 \\
\hline & Change in frequency of sex & No change & $62.9 \%$ & $75.0 \%$ & 0.18 \\
\hline & Change in sexual pleasure & Increase & $34.3 \%$ & $25.0 \%$ & 1.00 \\
\hline Will use in future & Interested & Yes & $91.8 \%$ & $50.0 \%$ & 0.00 \\
\hline $\begin{array}{l}\text { Partner/family } \\
\text { would support use }\end{array}$ & Reported & Yes & $86.5 \%$ & $0.0 \%$ & 0.00 \\
\hline Will recommend & Reported & Yes & $91.9 \%$ & $50.0 \%$ & 0.03 \\
\hline $\begin{array}{l}\text { Already } \\
\text { recommended }\end{array}$ & Reported & Yes & $73.0 \%$ & $50.0 \%$ & 0.04 \\
\hline Willingness to pay & Interested & Yes & $76.5 \%$ & $0.0 \%$ & 0.07 \\
\hline
\end{tabular}

Data source: Follow-up dataset.

The results in Table 6 further show that a higher proportion of satisfied than dissatisfied participants did not experience expulsions ( $86 \%$ and $67 \%$, respectively), did not feel the ring during sexual intercourse $(89 \%$ and $50 \%$, respectively), did not report partners feeling the ring during sexual intercourse $(63 \%$ and $25 \%$, respectively), and indicated that their sexual pleasure increased during the time they were using the ring (34\% and $25 \%$, respectively). In addition, a higher proportion of satisfied than dissatisfied participants reported that they would use the ring in the future ( $92 \%$ and $50 \%$, respectively), their partners and family members would support them in using the ring in the future ( $87 \%$ versus $0 \%$, respectively), they would recommend the use of the ring to friends and family members ( $92 \%$ and $50 \%$, respectively), they had already recommended the ring to family members or friends ( $73 \%$ and $50 \%$, respectively), and that they would be willing to pay for the method ( $77 \%$ and $0 \%$, respectively). Further analysis showed that those who reported willingness to pay for the method cited amounts ranging from KSh. 50 ( US\$0.50) to KSh. 1,000 ( US\$10) with a median of KSh. 200 ( US\$2). 
Providers further reported that they received clients who were often referred by PVR users asking for the ring. They further reported that some of the participants who had completed the two ring cycles wanted another ring (which could not be provided outside the context of the study). Some of the participants also wanted a ring that could be used for one year or more.

\section{WOMEN PARTICIPANTS}

Satisfaction with the ring was also evident from the in-depth interviews with clients who were enrolled for qualitative interviews as exemplified by the excerpts in Table 7.

TABLE 7 Responses by satisfaction related to PVR use

\begin{tabular}{|c|c|}
\hline Domain & Comments \\
\hline \multirow[t]{2}{*}{$\begin{array}{l}\text { Perceptions of } \\
\text { PVR }\end{array}$} & $\begin{array}{l}\text { It's easy to use it, especially compared to the pill. You don't } \\
\text { "forget" to take it, because it's always there. (PVR User, Kiambu } \\
\text { County) }\end{array}$ \\
\hline & $\begin{array}{l}\text { It can be removed ... that is one of the things that made me like } \\
\text { it.... [If] I feel that it is not good for me, then I can remove it and } \\
\text { shift to another [method]. (PVR User, Nairobi County) }\end{array}$ \\
\hline Partner's feelings about PVR & $\begin{array}{l}\text { We were discussing this and he was saying that that is the best } \\
\text { method because with the others I've had abdominal pain, } \\
\text { bleeding, and so on. Also, when using the other methods, } \\
\text { sometimes you feel like you don't want to have sex, but with the } \\
\text { ring I was very okay. (PVR User, Kiambu County) }\end{array}$ \\
\hline $\begin{array}{l}\text { Sharing experiences with } \\
\text { friends }\end{array}$ & $\begin{array}{l}\text { I told them it's good. It's stress-free and doesn't have side- } \\
\text { effects, like headaches. (PVR User, Kiambu County) }\end{array}$ \\
\hline
\end{tabular}

Data source: In-depth interviews with women.

\section{MALE PARTNERS}

Male partners of PVR users also found the ring acceptable and recommended a longer-lasting ring as shown by the quotes in Table 8.

TABLE 8 Responses by satisfaction related to PVR use

\begin{tabular}{|c|c|}
\hline Domain & Comments \\
\hline \multirow[t]{2}{*}{ Perceptions of PVR } & $\begin{array}{l}\text { I liked it. It didn't interfere with breast-milk production or the } \\
\text { sexual desire of my wife. I only wish that a long-acting PVR is } \\
\text { introduced. That would help us a lot. (Partner of PVR User, } \\
\text { Kiambu County) }\end{array}$ \\
\hline & $\begin{array}{l}\text { It's very beneficial and user-friendly; it also does not interfere } \\
\text { with the flow of breast milk. (Partner of PVR User, Nairobi } \\
\text { County) }\end{array}$ \\
\hline $\begin{array}{l}\text { Recommendations for } \\
\text { the future }\end{array}$ & $\begin{array}{l}\text { The ring should be made as an annual one that should be } \\
\text { removed after one year. (Partner of PVR User, Kiambu } \\
\text { County) }\end{array}$ \\
\hline
\end{tabular}

Data source: In-depth interviews with husbands. 


\section{PROVIDERS' IMPRESSIONS}

Interviews with providers showed notable changes in their perceptions about the ring between baseline and endline. At endline, all providers reported that the ring was safe for postpartum women and for the infant and that they would recommend it to family members or friends (Table 9). In contrast, slightly more than half of the providers $(57 \%)$ felt that the ring was safe for postpartum women and the infant at baseline, while less than $9 \%$ indicated that they would recommend it to family members or friends. Similarly, nearly all providers (97\%) at endline indicated that women in their locality would like the ring compared with just about half at baseline. A similar proportion of providers (97\%) reported at endline that they would prescribe the ring to lactating women after the study ends.

The results in Table 9 further show that there were notable changes between baseline and endline in the proportion of providers that reported that community health workers should be allowed to dispense the ring (from $17 \%$ to $67 \%$ ), the ring does not affect sexual pleasure (from $51 \%$ to $83 \%$ ), the ring does not interfere with sexual intercourse (from $57 \%$ to $93 \%$ ), they would dispense the ring to lactating unmarried women with no contraindications (from $9 \%$ to $87 \%$ ), and that they would not require the husband's consent before dispensing the ring (from 9\% to 83\%). In addition, most of the providers (93\%) reported at endline that they did not receive any complaints from husbands/partners of study participants regarding the use of the ring, while about half (53\%) reported that they did not receive any complaints from users. The smallest increase was in the proportion of providers who felt that the ring does not increase risk of vaginal or pelvic infections (from $37 \%$ at baseline to $57 \%$ at endline).

TABLE 9 Providers' responses by satisfaction related to PVR use

\begin{tabular}{llc}
\hline Domain & $\begin{array}{c}\text { Baseline } \\
(\mathrm{N}=35)\end{array}$ & $\begin{array}{c}\text { Endline } \\
(\mathrm{N}=30)\end{array}$ \\
\hline PVR is safe for postpartum women & $57.1 \%$ & $100.0 \%$ \\
PVR is safe for baby & $57.1 \%$ & $100.0 \%$ \\
PVR does not increase risk of vaginal/pelvic infections & $37.1 \%$ & $56.7 \%$ \\
Lactating women in the locality would like PVR & $54.3 \%$ & $96.7 \%$ \\
Community health workers should be allowed to dispense PVR & $17.1 \%$ & $66.7 \%$ \\
PVR does not affect sexual pleasure & $51.4 \%$ & $83.3 \%$ \\
PVR does not interfere with sexual intercourse & $57.1 \%$ & $93.3 \%$ \\
Would recommend PVR to family members/friends & $8.6 \%$ & $100.0 \%$ \\
Would provide PVR to unmarried women with no contraindications & $8.6 \%$ & $86.7 \%$ \\
Would not require husband's consent before dispensing PVR & $8.6 \%$ & $83.3 \%$ \\
Did not receive any complaints from clients regarding PVR use & - & $53.3 \%$ \\
Did not receive any complaints from spouses/partners regarding PVR & - & $93.3 \%$ \\
Use & & $96.7 \%$ \\
\hline Wata source: Provider interviews at baseline and endline & - & \\
\hline
\end{tabular}




\section{COMMUNITY STAKEHOLDERS}

Findings from focus group discussions with community stakeholders showed that the ring was acceptable for various reasons, including convenience and ease of use, as shown by the quotes in Table 10.

TABLE 10 Responses by satisfaction related to community members' PVR use

\begin{tabular}{|l|l}
\hline Domain & \multicolumn{1}{l}{ Comments } \\
\hline Perceptions of PVR & [The PVR] is the best way since it will not cause any problems even if \\
breastfeeding. Breastfeeding women can sometimes get pregnant before 6 \\
months and that is a problem for men since they will be denied sex with \\
women. (Community Leaders, Kiambu County) \\
[The PVR] will be considered easy and cheap to use. Women have a lot of \\
issues: You will find that your husband was out on a trip, comes back \\
abruptly, and wants to leave just as quickly. Then you realize that you \\
haven't taken your pill and he wants to have sex. Do you think you'll tell him \\
to wait until you take the pill first when you've probably been hiding it from \\
him? Definitely not. So, to avoid such awkward moments, I would rather use \\
the vaginal ring to be safe at all times. (Community Leaders, Nairobi County)
\end{tabular}

Data source: Focus-group discussion.

\section{PARTNERS' SUPPORT AND EXPERIENCE}

Half of the participants who were interviewed during follow-up and who reported that they had resumed sexual intercourse indicated that their partners felt the ring (Figure 4). Slightly more than one-third (36\%) indicated that the ring negatively affected their partners' sexual pleasure, with $41 \%$ indicating that the partners' sexual pleasure increased. Further analysis showed that a higher proportion of participants who completed the two ring cycles, compared with those who terminated use, reported that their partners felt the ring during sexual intercourse (52\% and $47 \%$, respectively); that the ring affected their partners' sexual pleasure (40\% and 32\%, respectively); and that their partners' sexual pleasure increased (56\% and $21 \%$, respectively).

Increase in partners' sexual experience was further reflected in the in-depth interviews. As one user who was enrolled for in-depth interviews put it:

I can tell women [that] if they use [the ring], even their husbands will say, "Ah! ... the act in bed ... they [men] say it's good ... He says it's because of the ring. (In-depth interview, Kiambu County)

Field reports also showed that a few participants were accompanied by their spouses who helped in decisionmaking regarding the choice of the ring. In one case, a participant who had completed the two ring cycles and switched to another method was told by the husband to return to the facility and take up another ring. However, there were also a few participants who after being counseled, reported that they had to consult their husbands before they could take up the ring. In addition, as already noted, one client discontinued use because she reported that her husband was not comfortable with the ring. 


\section{DISCONTINUATION}

Twenty-six of the 60 participants (43\%) who enrolled for follow-up completed two ring cycles, 24 (40\%) discontinued use for various reasons (Figure 4), while 10 (17\%) were lost to follow-up. Table 11 presents the distribution of participants who completed the two ring cycles and those who terminated use by experiences with the ring. The proportion of participants who found the ring easy to insert was higher among those who completed the two ring cycles than among those who terminated use ( $77 \%$ and $63 \%$, respectively). In contrast, the proportion of participants who found the ring easy to remove was higher among those who terminated use than among those who completed the two ring cycles ( $54 \%$ and $46 \%$, respectively). Similarly, all women who completed the two ring cycles did not experience expulsion. The proportion that did not experience expulsion was much lower among those who terminated use (68\%).

TABLE 11 Responses by continuation related to PVR use

\begin{tabular}{lllrrr}
\hline Domain & Item & Response & $\begin{array}{c}\text { Continued } \\
(\mathrm{N}=26)\end{array}$ & $\begin{array}{c}\text { Terminated } \\
(\mathrm{N}=24)\end{array}$ & $\begin{array}{c}\text { P Value } \\
\text { Fisher's Exact Test }\end{array}$ \\
\hline \multirow{2}{*}{ Ease of use } & Ease of inserting PVR & Easy/Very easy & $76.9 \%$ & $62.5 \%$ & 0.36 \\
& Ease of removing PVR & Easy/Very easy & $46.2 \%$ & $54.2 \%$ & 0.78 \\
& Ease of reinserting PVR & Easy/Very easy & $53.9 \%$ & $54.2 \%$ & 1.00 \\
Expulsion & PVR fell out on its own & No & $100.0 \%$ & $68.4 \%$ & 0.00 \\
& Frequency of feeling the PVR & No, never & $68.0 \%$ & $52.6 \%$ & 0.36 \\
Sexual & Feel PVR during sex & No & $92.0 \%$ & $57.9 \%$ & 0.01 \\
intercourse & Partner feels PVR during sex & No & $76.0 \%$ & $31.6 \%$ & 0.01 \\
& Removal during sex & No & $100.0 \%$ & $94.7 \%$ & 0.43 \\
& Change in frequency of sex & No change or increase & $96.0 \%$ & $84.2 \%$ & 0.30 \\
& Change in sexual pleasure & No change or increase & $96.0 \%$ & $73.7 \%$ & 0.07
\end{tabular}

Data source: Baseline and follow-up datasets.

The results in Table 11 further show that the proportion of participants who did not feel the ring during sex was higher among those who completed the two ring cycles than among those who terminated use $(92 \%$ and $58 \%$, respectively). Similar differences between those who completed two ring cycles and those who terminated use were noted in the proportion of participants whose partners did not feel the ring during sex $(76 \%$ and $32 \%$, respectively) as well as those who did not experience any change or experienced an increase in the frequency of sex ( $96 \%$ and $84 \%$, respectively) or sexual pleasure ( $96 \%$ and $74 \%$, respectively).

The most common reason for discontinuing use of the ring was expulsion (Figure 5). Another 10 participants were lost to follow-up having moved out of the study setting or due to incorrect contact information, while 5 discontinued use because they reported experiencing side effects including abdominal pain, vaginal bleeding, and loss of libido. Three participants were discontinued due to non-adherence to study procedures, because they left the ring out for more than two hours. One participant stopped use because she associated the illness of one of her twin babies to the use of the ring (i.e., misconception about the method).

\section{FIGURE 5 REASONS FOR DISCONTINUING PVR}

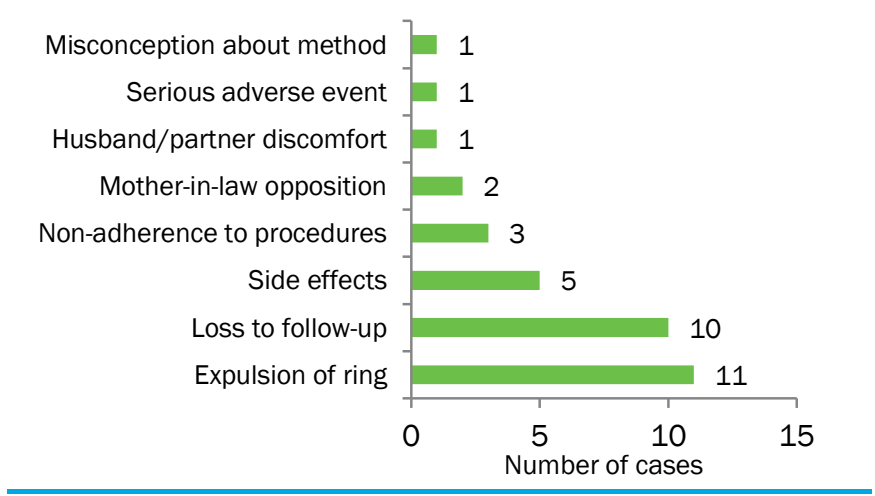

Data source: Follow-up dataset $(\mathrm{N}=34)$. 
Figure 6 presents the distribution of participants who completed the two ring cycles and those who terminated participation but were interviewed at follow-up by type of method they switched to. The proportion of participants who switched to injectables was higher among those who terminated use than among those who completed the two ring cycles ( $72 \%$ and $6 \%$, respectively). In contrast, the proportion of participants who switched to implants was higher among those who completed the two ring cycles than among those who terminated use (56\% and $17 \%$, respectively). Similar variations were noted with respect to switching to the IUD (25\% among those who completed the two ring cycles compared with $6 \%$ among those who terminated use).

\section{FIGURE 6 METHOD SWITCH}

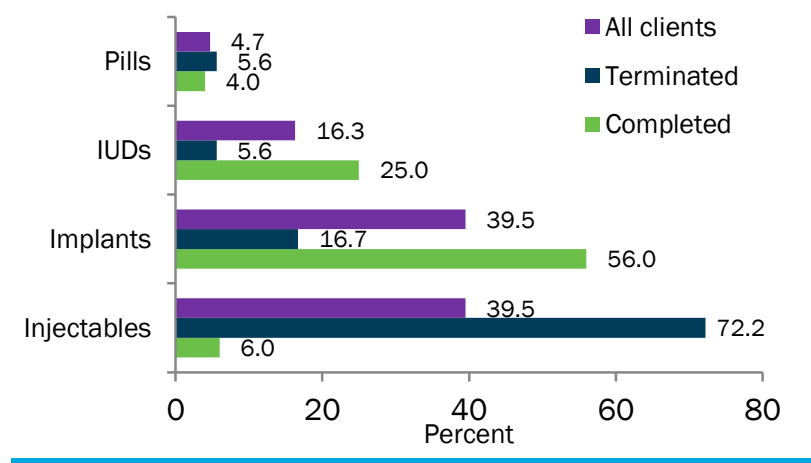

Data source: Follow-up dataset $(\mathrm{N}=43)$.

Further analysis showed that the proportion of participants who had ever used injectables was almost similar among those who completed the two ring cycles and those who terminated use (40\% and $38 \%$, respectively). However, a higher proportion of participants who completed the two ring cycles had ever used pills compared with those who terminated use (67\% and 38\%, respectively). A similar pattern was noted for the IUD, with $13 \%$ of those who completed the two cycles having previously used the method compared with none among those who terminated use. In contrast, the proportion that had ever used implants was nearly twice as high among those who terminated use compared with those who completed the two cycles (13\% and $7 \%$ ).

\section{ADVERSE AND SERIOUS ADVERSE EVENTS}

Tables 12 and 13 list the adverse and serious adverse events that occurred in the course of the study. There were a total of three adverse events and one serious adverse event. The first adverse event was a mild urinary tract infection, which was treated. The provider determined the relationship of the condition with the product as "possible." However, the participant continued using the ring and completed the two ring cycles.

The second adverse event involved complaints about lower abdominal pains, which the provider determined did not require treatment but was possibly related to the study product. The participant also reported that her husband had told her to remove the ring as a result. Her participation in the study was therefore terminated.
TABLE 12 Adverse events

\begin{tabular}{lll}
\hline Number & Description & Treatment \\
\hline KE14104 & Mild urinary tract infection & Treated and discharged \\
KE14108 & Lower abdominal pain & No treatment required \\
KE16101 & Prolonged bleeding & Treated and discharged \\
\hline
\end{tabular}

Data source: Case record forms.

TABLE 13 Serious adverse events

\begin{tabular}{lll}
\hline Number & Description & Treatment \\
\hline KE16102 & $\begin{array}{l}\text { Severe headache } \\
\text { and psychosis }\end{array}$ & $\begin{array}{l}\text { Treated in a } \\
\text { nonparticipating facility }\end{array}$ \\
\hline
\end{tabular}

Data source: Case record forms.

The third adverse event involved prolonged bleeding, which the provider determined was possibly related to the study product. The participant sought treatment from a nonparticipating facility where she was advised to remove the ring. The provider therefore decided to terminate her participation in the study. The condition for the serious adverse event could not be conclusively determined because the participant sought care from a nonparticipating facility. The case was, however, considered a serious adverse event because the participant was hospitalized while still in the study. The study team realized that there was a serious adverse event when the client failed to return for a scheduled visit and attempted to follow up. However, the provider indicated that the condition was severe headache and psychosis based on the report of the mother-in-law and that it was unlikely related to the study product. The information was shared with the Population Council's Safety Desk for determination as well. The Safety Desk then developed a report, which was shared with the local regulatory authorities. 


\section{Discussion}

\section{ACCEPTABILITY}

A number of key findings emerged from this study that will be useful for future introduction efforts. Most importantly, the ring was acceptable to most users, partners, providers, and other community members. The majority of participants who completed the two ring cycles indicated that they would use the ring in the future, their partners or family members would support future use, they would recommend or had already recommended the ring to their friends or family members, and that they were willing to pay for the method. In addition, some clients were encouraged by their spouses to use the ring. There were also remarkable positive changes between baseline and follow-up in the perceptions of participants and providers about the ring. These are indications that the ring was acceptable to clients and key stakeholders. Acceptability of the ring to clients and key stakeholders is, in turn, important for informing the introduction of the method into the country.

Several attributes associated with the ring are likely to contribute to increased uptake of the method. The most commonly cited reason for the choice of the ring among users was that the method is user-controlled. Most users also found the ring easy to insert, remove, and reinsert. Such attributes are likely to increase the uptake of the method in the country. This is also consistent with findings from studies in other settings such as Australia, Canada, Chile, the Dominican Republic, and the United States that found that women liked vaginal rings for the same reasons (RHSC 2011).

In addition, the majority of users were young, educated, urban or peri-urban dwellers. The majority of women who chose the ring were aged 20-29 years, had at least secondary level education, and resided in urban or peri-urban areas. In addition, the majority of PVR users had given birth to at least two children and wanted to space the next birth by at least four years. These findings are consistent with those of market segmentation analysis of existing Demographic and Health Survey data using a needs-based approach, which showed that most users of the ring are likely to have these attributes (Obare et al. 2014). The findings suggest that these categories of clients are likely to be the first acceptors of the method if it is introduced into the country before usage diffuses to other segments of the population.

Next, the PVR is likely to expand contraceptive choices during the postpartum period. The second major reason for choosing the ring was the perception of fewer side effects. In addition, some clients chose the ring just to try a new method, while others chose it because their preferred method was not available at the time of the visit. Given that the postpartum period is characterized by high unmet need for contraception and a limited range of available methods, expanding contraceptive choices for postpartum women has been a key priority of the Ministry of Health (DRH 2010; KNBS and ICF Macro 2010).

Expanding method choices is likely to sustain or to contribute to an increased contraceptive prevalence rate. Slightly more than one-third of PVR users were new family planning users. The goal of the Ministry of Health was to achieve a contraceptive prevalence rate of $56 \%$ by 2015. Findings from the 2014 KDHS showed that the prevalence rate had increased to 58\% from 46\% in 2008-09 (KNBS and ICF Macro 2010; KNBS et al. 2015). By drawing in new users, the ring is likely to sustain the prevailing contraceptive prevalence rate or contribute to a further increase provided efforts are put in place to support users and providers and to reduce discontinuation.

Finally, the PVR is likely to bridge users to long-term methods, especially those involving insertion. The findings of the study showed that those who completed two ring cycles were more likely to switch to implants or IUDs compared with those who terminated use. Switching to long-term methods was also consistent with the finding that most users wished to space the next pregnancy by at least four years. The finding further suggests that the ring is likely to contribute to increased uptake of methods involving insertion and trained providers. 


\section{LIMITATIONS}

The above findings could be influenced by the following study limitations. The target sample size of 58 clients for follow-up was small. However, as already noted, the sample size was powered to detect significant differences for the three countries combined (Kenya, Nigeria, and Senegal) with 58 clients targeted in each country. Given that the study involved prospective follow-up of clients, it was affected by loss to follow-up mostly occasioned by participants moving out of the study area or providing incorrect contact information. However, the rate of loss to follow-up (17\%) was within the recommended minimum of between $20 \%$ and $30 \%$ for cohort studies (Babbie 1973; Altman 2000). Finally, discontinuation was mainly due to experiences of ring expulsion followed by side effects and non-adherence to use procedures. Ring expulsion and non-adherence to use procedures were found to be the second most common reasons for termination of ring use in other studies (Diaz et al. 1997; Sivin et al. 1997; Massai et al. 1999, 2005). The rate of discontinuation of ring use in the study (40\%) was also comparable to, or lower than, that of other methods in the country. For instance, estimates from 2008-09 KDHS show that the rate of discontinuation was 29\% for injectables, $43 \%$ for pills, $59 \%$ for condoms, and 36\% for all methods (KNBS and ICF Macro 2010).

\section{LESSONS LEARNED FOR FUTURE INTRODUCTION OF RINGS}

The findings of the study have the following implications for future efforts geared toward introducing the ring in the country:

- Client counseling on proper use of the ring: Given that the ring is a user-controlled method, service delivery programs should consider ways of ensuring that clients obtain information on correct use including proper insertion and adherence to use instructions, such as not leaving the ring out for long. Proper insertion and adhering to use instructions are, in turn, likely to reduce instances of ring expulsion and discontinuation.

- Addressing misconceptions: Just like any other family planning method, programs delivering the ring need to consider addressing misconceptions about the method. This was evident from the finding that one client terminated use because she associated the illness of one of her twins with the use of the ring. In addition, it is likely that those who terminated use because of the influence of mothers-in-law or spouses could partly be due to misconceptions about the method on the part of these significant others.

- Mechanisms for bridging users to long-term methods: It was evident that those who completed the two ring cycles mostly switched to long-term methods at the end of the study. In addition, most users desired longer birth spacing. Programs delivering the ring therefore need to consider mechanisms for bridging users to long-term methods. 


\section{References}

Altman, D.G. 2000. "Statistics in medical journals: Some recent trends." Statistics in Medicine 19: 32753289.

Babbie, E.R. 1973. Survey Research Methods. Belmont, CA: Wadsworth.

Central Bureau of Statistics (CBS) [Kenya], Ministry of Health (MOH) [Kenya], and ORC Macro. 2004. Kenya Demographic and Health Survey 2003. Calverton, MD: CBS, MOH, and ORC Macro.

Chebet, K. and R. Jahonga. 2011. "Experiences with the postpartum intrauterine contraceptive device (PPIUCD) in Eastern Province, Kenya." Paper presented at the 2011 International Conference on Family Planning, Dakar, Senegal, 29 November to 2 December.

Diaz, S., A. Zepeda, X. Maturana, M.V. Reyes, P. Miranda, M.E. Casado, et al. 1997. “Fertility regulation in nursing women. IX. Contraceptive performance, duration of lactation, infant growth, and bleeding patterns during use of progesterone vaginal rings, progestin-only pills, Norplant implants, and Copper T 380-A intrauterine devices." Contraception 56: 223-232.

Division of Reproductive Health (DRH)/Ministry of Public Health and Sanitation (MOPHS). 2010. National Family Planning Guidelines for Service Providers. Nairobi: DRH/MOPHS.

Gebreselassie T., S.O. Rutstein, and V. Mishra. 2008. "Contraceptive use, breastfeeding, amenorrhea and abstinence during the postpartum period: An analysis of four countries." Analytical Studies No. 14. Calverton, MD: Macro International.

Haggerty, P.A. and S.O. Rutstein. 1999. "Breastfeeding and complementary infant feeding, and the postpartum effects of breastfeeding." DHS Comparative Studies No. 30. Calverton, Maryland: Macro International.

Hsieh, H.F. and S.E. Shannon. 2005. "Three approaches to qualitative content analysis." Qualitative Health Research 15(19): 1277-1288.

Kenya National Bureau of Statistics (KNBS) and ICF Macro. 2010. Kenya Demographic and Health Survey 2008-09. Calverton, MD: KNBS and ICF Macro.

Kenya National Bureau of Statistics (KNBS), Ministry of Health (MOH) [Kenya], National AIDS Control Council (NACC) [Kenya], Kenya Medical Research Institute (KEMRI), and National Council for Population and Development (NCPD) [Kenya]. 2015. Kenya Demographic and Health Survey 2014: Key Indicators. Nairobi: KNBS, MOH, NACC, KEMRI, and NCPD.

Maina, B. 2012. The Breast Milk Substitutes Law Is Not About Breastfeeding. http://www.africasciencenews.org/en/index.php?option=com_content\&view=article\&id=630:the-breast-milksubstitutes-law-is-not-about-breast-feeding\&catid=63:health\&ltemid=114. Accessed 4 December 2012.

Massai, R., P. Miranda, P. Valdes, P. Lavin, A. Zepeda, M.E. Casado, et al. 1999. "Pre-registration study on the safety and contraceptive efficacy of a progesterone-releasing vaginal ring in Chilean nursing women." Contraception 60: 9-14.

Massai, R., E. Quinteros, M.V. Reyes, R. Caviedes, A. Zepeda, J.C. Montero, et al. 2005. "Extended use of a progesterone-releasing vaginal ring in nursing women: A phase II clinical trial." Contraception 72: 352-57. 
Mwangi, A., C. Warren, N. Koskei, and H. Blanchard. 2008. "Strengthening postnatal care services including postpartum family planning in Kenya." Nairobi: Frontiers/Population Council.

National Council for Population and Development (NCPD) [Kenya], Central Bureau of Statistics (CBS) [Kenya], and Macro International. 1999. Kenya Demographic and Health Survey 1998. Calverton, MD: NCPD, CBS, and Macro International.

National Council for Population and Development [NCPD] and Institute for Resource Development/Macro Systems. 1989. Kenya Demographic and Health Survey 1989. Columbia, MD: NCPD and Institute for Resource Development/Macro Systems.

Obare, F., D. Rajamani, and S. RamaRao. 2014. "Assessing the potential market for a progesterone contraceptive vaginal ring (PVR) as a new contraceptive option in sub-Saharan Africa using needs-based market segmentation." Report. New York: Population Council.

Reproductive Health Supplies Coalition [RHSC]. 2011. "Progesterone-only vaginal rings." Product Brief, Caucus on New and Underused Reproductive Health Technologies, January 2011.

Republic of Kenya/Ministry of Public Health and Sanitation. 2012. "The World Breastfeeding Trends Initiative (WBTi): Kenya." Nairobi: Republic of Kenya/Ministry of Public Health and Sanitation.

Sivin, I., S. Diaz, H.B. Croxatto, P. Miranda, M. Shaaban, E.H. Sayed, et al. 1997. "Contraceptives for lactating women: A comparative trial of a progesterone-releasing vaginal ring and the copper T 380A IUD."

Contraception 55: 225-232.

Westoff, C.F. 2012. “Unmet need for contraceptive methods.” DHS Analytical Studies 28. Calverton, MD: ICF International. 


\section{Appendix}

\section{APPENDIX A1: INCLUSION/EXCLUSION CRITERIA}

\section{A. INCLUSION CRITERIA}

To participate in the study, a woman had to meet all the inclusion criteria listed below at enrollment:

1. Able to provide informed consent

2. Age 18 to 35 years (inclusive)

3. Delivered a healthy singleton infant 6 to 9 weeks prior to study enrollment

4. Has at least (1) living child and is fully/nearly fully breastfeeding the new infant

5. Willing to continue breastfeeding infant a minimum of 4 times per day for at least 6 months.

6. Is in good health as confirmed by medical history, physical examination. (Includes vital signs and diagnosis/treatment of vaginal infection per the standard of care in Kenya. Treatment of vaginal infection is required prior to enrollment.)

7. Has or expects to have regular exposure to the risk of pregnancy

8. Willing to choose the PVR as contraceptive method

9. Willing and able to follow study procedures

10. Expects to continue living in an area accessible to the study site for the duration of the study.

\section{B. EXCLUSION CRITERIA}

Similarly, women with any of the following attributes were excluded from participating in the study:

1. Is pregnant or suspected of being pregnant

2. Breastfeeding less than fully/nearly fully

3. Hypersensitivity to hormonal preparations or silicone rubber

4. HIV positive or in a discordant relationship

5. Presence of genital or urinary tract infection

6. Dyspareunia

7. History of Human Papillomavirus (HPV)

8. History of bacterial infections such as Chlamydia and gonorrhea

9. History of pelvic inflammatory disease (PID) or salpingitis since delivery

10. History of chronic constipation

11. Clinically relevant genital prolapse

12. Has history of generalized urticaria

13. Any chronic condition requiring continuous or regular use of medication or herbals prescribed by healers

14. Has a history of thrombophlebitis or thromboembolism

15. History of and/or current depression

16. History of epilepsy or convulsive disorder

17. Had an ectopic pregnancy

18. Has vaginal bleeding not attributable to menses

19. Known or suspected carcinoma of the breast

20. Has had any other known or suspected neoplasia within last 5 years

21. Not exposed to risk of pregnancy

22. Use of chronic medications, Rifampicin, Griseofluvin, barbiturates, phenytoin, ketoconozole, butazoliden

23. Confirmed hypertension (blood pressure-systolic more than $140 \mathrm{mmHg}$ and/or diastolic more than 90 $\mathrm{mmHg}$ ) 

Population Council General Accident House Ralph Bunche Road Nairobi, Kenya popcouncil.org 